\title{
Surveillance of Populations at Risk of Cholangiocarcinoma Development in Rural Communities of Thailand Using the Korat-CCA Verbal Screening Test
}

Soraya J Kaewpitoon ${ }^{1,2,3 *}$, Ratana Rujirakul ${ }^{1}$, Ryan A Loyd ${ }^{2,3}$, Sukij Panpimanmas $^{3,4}$, Likit Matrakool ${ }^{3,4}$, Taweesak Tongtawee ${ }^{3,4}$, Porntip Kompor ${ }^{5}$, Jun Norkaew $^{5}$, Wasugree Chavengkun ${ }^{5}$, Parichart Wakkhuwattapong ${ }^{1}$, Jirawoot Kujapun ${ }^{5}$, Sukanya Ponphimai ${ }^{5}$, Tanida Phatisena ${ }^{6}$, Thawatchai Eaksunti ${ }^{6}$, Poowadol Polsripradist ${ }^{7}$, Apinya Joosiri ${ }^{1,3}$, Inchat Sukkasam ${ }^{8}$, Natnapa Padchasuwan', Natthawut Kaewpitoon $^{1,3,5}$

\begin{abstract}
Cholangiocarcinoma (CCA) is a serious problem in Thailand, particularly in the northeastern region. Active surveillance in rural communities with an appropriat low-cost screening tool is required to facilitate early detection. Therefore, this study aimed to investigate the population at risk of CCA in Bua Yai district, Nakhon Ratchasima province, Northeastern Thailand using the Korat-CCA verbal screening test (KCVST) during June to October 2015. Reliability of KCVST demonstrated a Cronbach alpha coefficient $=0.75$ Stepwise-multiple regression showed that alcohol consumption was important for CCA screened, followed by agriculture and pesticide use, under-cooked cyprinoid fish consumption, praziquantel use, naïve northeastern people, opisthorchiasis, family relatives with CCA, and cholangitis or cholecystitis or gallstones, respectively. Population at risk for CCA was classified to low risk $(63.4 \%)$, moderate risk $(33.7 \%)$, and high risk $(1.32 \%)$ for CCA. When CCA was screened using ultrasonography, 4 of 32 high risk participants had an abnormal biliary tract with dilated bile ducts. This study indicates that KCVST is a potential useful too which decrease the cost of large scale CCA screening.
\end{abstract}

Keywords: Cholangiocarcinoma - surveillance - Korat-CCA verbal screening test - Thailand

Asian Pac J Cancer Prev, 17 (4), 2205-2209

\section{Introduction}

Cholangiocarcinoma (CCA) is neoplasm that involves the epithelial cells of the bile duct. CCA is originated in the bile duct in which drained bile from the liver into the small intestine. It is also known to be one of the most common causes of cancer related to death in Thailand and it has been reported that Thailand is the highest incident of the world (Green et al., 1991; Sripa et al., 2007; Shin et al., 2010). It has an annual incidence rate of 1-2 cases per 100,000 in the Western world, but rates of CCA have been rising worldwide over the past several decades (Landis et al., 1998; Patel, 2002).

This disease is difficult to have early diagnosis, as most symptoms present late in the disease course. In addition, the specific anatomic position can cause periductal extension and result in a very low radical excision rate and a very poor prognosis. Furthermore, CCA is considered to be an incurable and rapidly lethal disease unless all the tumors can be fully resected. Three-year survival rates of $35 \%$ to $50 \%$ are achieved only in a subset of patients who have negative histological margins at the time of surgery (Akamatsu et al., 2011). Survival of CCA patients in northeastern Thailand after supportive treatment was reported and indicated that the stage of disease was an important prognosis factor affecting survival of CCA patients who had diagnosis in late stage. To e encourage patients to see health personnel at early stage is very important (Thunyaharn et al., 2013). Palliative therapeutic approaches, consisting of percutaneous and endoscopic

${ }^{1}$ Parasitic Disease Research Unit, ${ }^{2}$ School of Family Medicine and Community Medicine, ${ }^{3}$ Suranaree University of Technology Hospital, ${ }^{4}$ School of Surgery, Institute of Medicine, Suranaree University, ${ }^{5}$ Faculty of Public Health, Vongchavalitkul University, , ${ }^{6}$ Faculty of Public Health, Nakhon Ratchasima Rajabhat University, ${ }^{7}$ Provincial Public Health of Nakhon Ratchasima, ${ }^{8}$ The Office of Disease Prevention and Control of Nakhon Ratchasima, Nakhon Ratchasima, ${ }^{9}$ Faculty of Public Health, Khon Kaen University, Khon Kaen, Thailand *For correspondence: soraya.k@sut.ac.th 
biliary drainage, have usually been used for these patients because there is no effective chemotherapeutic treatment for this type of cancer.

Therefore, an active surveillance in the rural communities is need required and potential screening tool is useful for decreased a cost. This study aimed to investigate the population at risk for CCA in Bua Yai district, Nakhon Ratchasima province, Northeastern Thailand using Korat-CCA Verbal Screening Test (KCVST) during June to October 2015. Success data may useful for CCA screening in a large scale for CCA prevention and control.

\section{Materials and Methods}

A cross-sectional survey was a pilot project and conducted in Bua Yai district, Nakhon Ratchasima province, northeastern Thailand, between June and October 2015. Bua Yai is a district in the northern part of Nakhon Ratchasima, and neighboring districts are (from the north clockwise) Waeng Noi district of Khon Kaen province, Bua Lai, Sida, Non Daeng, Khong, Ban Lueam, and Kaeng Sanam Nang of Nakhon Ratchasima Province. Bua Yai district is subdivided into 10 sub-districts, and 121 villages. The district is subdivieded into Bua Yai, Huai Yang, Sema Yai, Don Tanin, Nong Bua Sa-at, Non Thonglang, Kut Chk, Dan Chang, Khun Thong, and Nong Chaeng Yai. The town of Bua Yai covers part of the subdistrict. This district is coverage areas $271.6 \mathrm{~km}^{2}(104.9$ sq $\mathrm{mi}$ ), and has 84,133 populations.

Populations at risk for CCA, were screened by using mini-verbal screening questionnaire name; Korat-CCA Verbal Screening Test: KCVST, contained general information (name, gender, age, address, and health catchment area), and the question (yes/no choices) of the history with (1) opisthorchiasis; definitive diagnosed by medical doctor or related officers, (2) cholangitis or cholecystitis or gallstones; definitive diagnosed by medical doctor or related officers, (3) relative family with CCA, (4) under-cooked cyprinoid fish consumption, (5) praziquantel used, (6) alcohol consumption, (7) agriculture and pesticide used, and (8) naïve northeastern people. All questions were literature reviewed and designed from that possible risk data and strongly associated to CCA, according Table 1. Eight questions using yes/no choices. The KCVST was tested before the study, we had tryout in 8 sub-districts of Bua Yai district, Nakhon Ratchasima (5 questionnaires/sub-district), Cronbach alpha coefficient was 0.75 .

Before the study, permission and collaboration of the head of the public health center and/or head of the subdistrict were obtained. Multi-stage sampling was used to select the participants in this studied. Briefly, total of 66,163 targets from 194,152 populations was selected with criteria of aged $\geq 30$ years old. The interviewers received an interview training of $1 \mathrm{~d}$. The study was conducted at weekends to increase the possibility of meeting people at home. The staff comprised 10 interview teams each

Table 1. Designing of Korat-CCA Verbal Screening Test: KCVST, Based on Possible Risk Associated to Cholangiocarcinoma

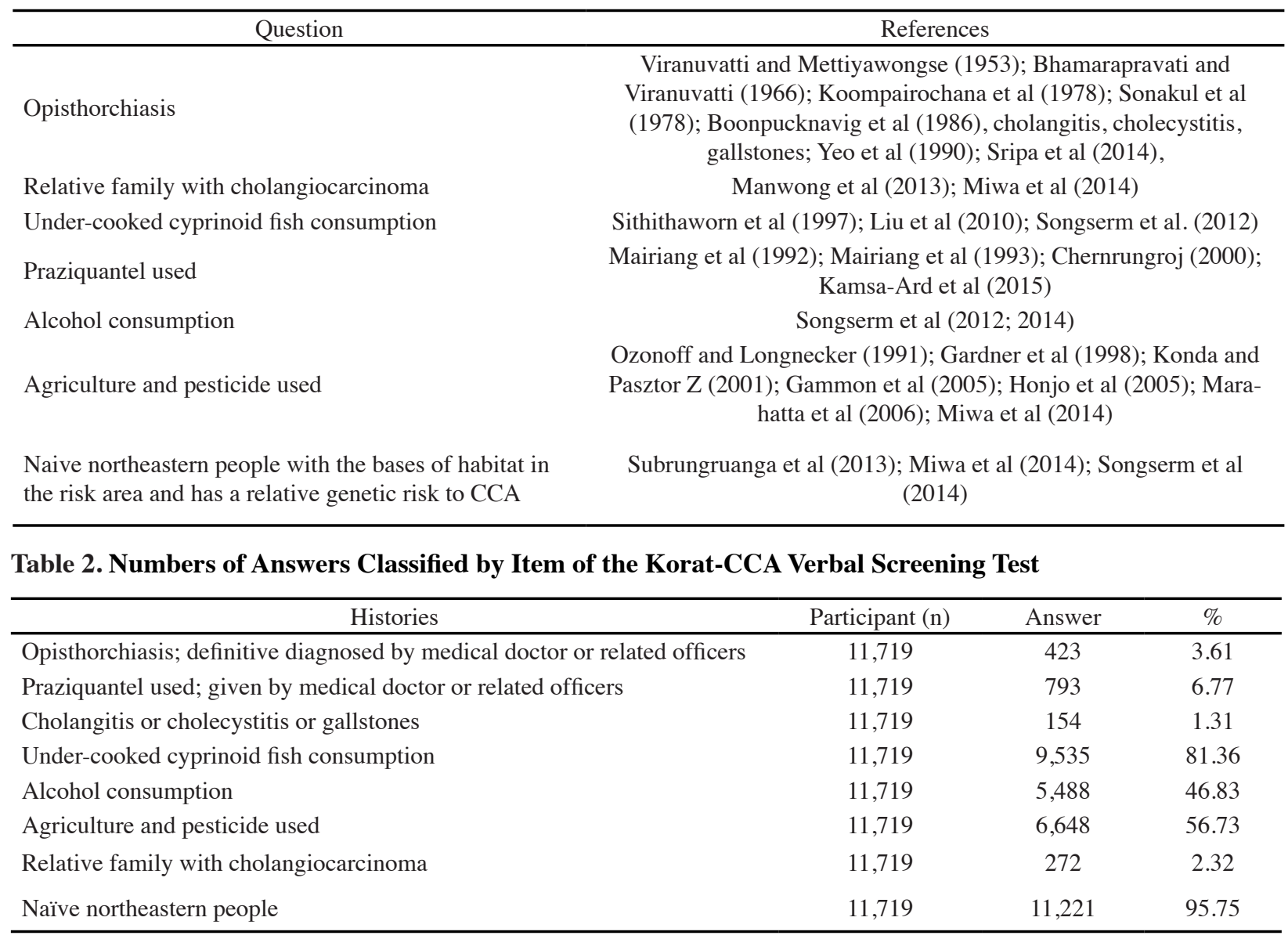


Surveillance of Populations at Risk for Cholangiocarcinoma in Rural Thailand Using the Korat-CCA Verbal Screening Test

Table 3. Item Weighting of Korat-CCA Verbal Screening Test Using Standardized B-Coefficient From StepwiseMultiple Regression Analysis

\begin{tabular}{|c|c|c|c|c|c|c|}
\hline \multirow[t]{2}{*}{ Questions } & \multicolumn{2}{|c|}{$\begin{array}{c}\text { Unstandardized } \\
\text { Coefficients }\end{array}$} & \multirow{2}{*}{$\begin{array}{c}\begin{array}{c}\text { Standardized } \\
\text { Coefficients }\end{array} \\
\text { Beta }\end{array}$} & \multirow[t]{2}{*}{$\mathrm{t}$} & \multirow[t]{2}{*}{ Sig } & \multirow[t]{2}{*}{$\begin{array}{l}\text { Partial } \\
\text { correlation }\end{array}$} \\
\hline & B & Std. Error & & & & \\
\hline Constant & 0.01 & 0.006 & & 1.713 & 0.087 & \\
\hline Alcohol consumption & 0.998 & 0.002 & 0.427 & 409.892 & 0.001 & 0.967 \\
\hline Agriculture and pesticide used & 0.988 & 0.003 & 0.419 & 391.777 & 0.001 & 0.964 \\
\hline Under-cooked cyprinoid fish consumption & 0.996 & 0.003 & 0.332 & 307.696 & 0.001 & 0.943 \\
\hline $\begin{array}{l}\text { Praziquantel used; given by medical doctor or } \\
\text { related officers }\end{array}$ & 0.992 & 0.005 & 0.214 & 196.252 & 0.001 & 0.876 \\
\hline Naïve northeastern people & 0.992 & 0.006 & 0.171 & 169.685 & 0.001 & 0.843 \\
\hline $\begin{array}{l}\text { Opisthorchiasis; definitive diagnosed by medical } \\
\text { doctor or related officer }\end{array}$ & 1.006 & 0.007 & 0.161 & 146.797 & 0.001 & 0.805 \\
\hline Relative family with cholangiocarcinoma & 0.995 & 0.008 & 0.128 & 128.917 & 0.001 & 0.766 \\
\hline Cholangitis or cholecystitis or gallstones & 1.016 & 0.01 & 0.099 & 98.537 & 0.001 & 0.673 \\
\hline
\end{tabular}

consisting of 5 interviewers (village health volunteer and public health officer) from district public health of Bua Yai. Each team was responsible for a number of households in the sub-district. A supervising team visited the members of each interview team to check their performance and questionnaires were checked for inconsistencies. When correction was deemed necessary, the interview team visited the study participants on the same day again to gather the missing information. All inhabitants in a study site were asked to participate in the study. The population at risk was calculated score following $1+2+3+4+5+6+7+8$, and classified into with high risk (6-8 points), moderate risk (4-5 point), and low risk (1-3 point). Stepwise multiple regression was used for analyzed the potential question to predict the risk group of CCA. Statistical data analysis was carried out using SPSS software version 12.0. The study protocol was approved by Suranaree University Ethical Review Committee, EC58-48.

\section{Results}

A total of 11,719 participants was included in this study. The majorities of participants were female $(56.5 \%)$, age group 51-60 years old (29.2\%) and 41-50 years old (27.9\%), Bua Yai sub-district (19.4\%) and Non Thonglang subdistrict (12.2\%). The majorities of number of answer were the question of naïve northeastern people and followed by under-cooked cyprinoid fish consumption, alcohol consumption, and agriculture and pesticide used (Table 2).

Item analysis of Korat-CCA verbal screening test, was weighting and found that alcohol consumption had an important weight for CCA screened $(\beta=0.427, \mathrm{t}=409.892$, $\mathrm{p}=0001$ ), and partial correlation $=0.967$, followed by agriculture and pesticide used, under-cooked cyprinoid fish consumption, praziquantel used, naïve northeastern people, opisthorchiasis, relative family with CCA, and cholangitis or cholecystitis or gallstones, respectively (Table 3).

Population at risk for CCA was classified to risk group and found that the majorities of answer had a low
Table 5. Population at Risk of Cholangiocarcinoma Using Korat-CCA Verbal Screening Test

\begin{tabular}{lcc}
\hline Risk Group & Frequencies & $\%$ \\
\hline None & 183 & 1.56 \\
Low & 7432 & 63.42 \\
Moderate & 3949 & 33.69 \\
High & 155 & 1.32 \\
\hline
\end{tabular}

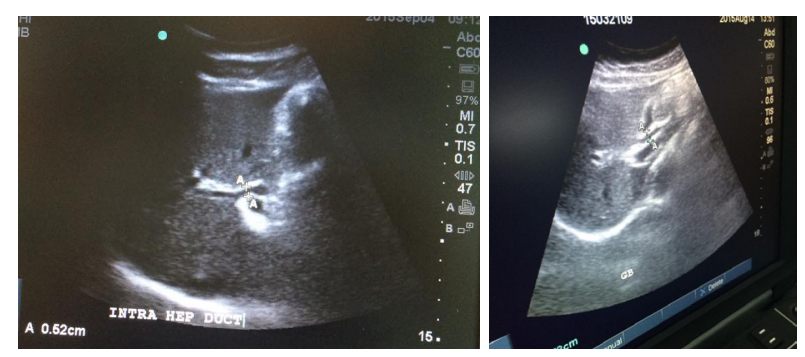

Figure 1. Dilation of Bile Duct of Participants Who had a High Risk Score with the Korat CCA Verbal Screening Test

risk $(63.4 \%)$, followed by moderate risk $(33.7 \%)$. While, the high risk for CCA was $1.32 \%$, and no risk group was $1.56 \%$ (Table 4 ). Ultrasonograpy was used for CCA screened, purposive selected of 32 participants who had a high risk scores, and found that 4 patients had dilated bile ducts (Figure 1).

\section{Discussion}

Based on published data in PubMed about the risk factor of CCA, here we designed and experience with a CCA verbal screening test as a name of Korat CCA verbal screening test; KCVST. KCVST had a reliability with Cronbach alpha coefficient $=0.75$ and found that alcohol consumption had an important weight for CCA screened $(\beta=0.427, \mathrm{t}=409.892, \mathrm{p}=0001)$, and partial correlation $=$ 0.967 , followed by agriculture and pesticide used, undercooked cyprinoid fish consumption, praziquantel used, naïve northeastern people, opisthorchiasis, relative family with CCA, and cholangitis or cholecystitis or gallstones, 
respectively. Previously reported that the patients who had histories with alcohol consumption, had a strongly associated to CCA (Songserm et al., 2012; 2014). In addition, there are many recent publications reporting on the high nitrogen species in the water reservoirs (Konda and Pásztor, 2001; Rabalai, 2002; Pilati et al., 2009). This is confirmed for the correlation to the contaminated pesticide in the water reservoirs (Gardner et al., 1998; Gammon et al., 2005). While, patient with opisthorchiasis (Viranuvatti and Mettiyawongse (1953); Bhamarapravati and Viranuvatti (1966); Koompairochana et al. (1978); Sonakul et al. (1978); Boonpucknavig et al (1986), cholangitis, cholecystitis, gallstones; Yeo et al (1990); Sripa et al. (2014)) and repeated praziquanltel used are strongly associated to CCA Mairiang et al. (1992); Mairiang et al. (1993); Kamsa-Ard et al. (2015).

A total of 11,719 participants, the majorities of number of answer were the question of naïve northeastern people and followed by under-cooked cyprinoid fish consumption, alcohol consumption, and agriculture and pesticide used. Population at risk for CCA was classified to risk group and found that the majorities of answer had a low risk (63.42\%), followed by moderate risk (33.69\%). While, the high risk for CCA was $1.32 \%$, and no risk group was $1.56 \%$. Ultrasonograpy was used for CCA screened, purposive selected of 32 participants who had a high risk scores, and found that 4 patients had a dilated bile ducts. This figure indicates that using of KCVST for screening CCA, is very simplified for answer and fastest analyzed by themselves. Participant took a time for answer approximately 2 minute/person and calculated their risk in the test.

In conclusion, KCVST is simplify, fast screen, decrease of cost, this tool may useful for CCA screening in a large scale for CCA prevention and control. Further study, Opisthorchis viverrini detection and CCA investigate with ultrasound in each risk group, are need to compare and analyze the correlation.

\section{References}

Akamatsu N, Sugawara Y, Hashimoto D. (2011). Surgical strategy for bile duct cancer: Advances and current limitations. World J Clin Oncol, 10, 94-107.

Bhamarapravati N, Viranuvatti W (1966). Liver diseases in Thailand. Analysis of liver biopsies. Am J Gastroenterol, 45, 267-76.

Boonpucknavig S, Kurathong S, Thamavit W (1986). Detection of antibodies in sera from patients with opisthorchiasis. $J$ Clin Lab Immunol, 19, 135-7.

Gammon DW, Aldous CN, Carr WC Jr, et al (2005). A risk assessment of atrazine use in California: human health and ecological aspects. Pest Manag Sci, 61, 331-55.

Gardner HS Jr, Brennan LM, Toussaint MW, et al (1998). Environmental complex mixture toxicity assessment. Environ Health Perspect, 106, 1299-305.

Green A, Uttaravichien T, Bhudhisawasdi V, et al. (1991). Cholangiocarcinoma in northeast Thailand. A hospital-based study. Trop Geogr Med, 43, 193-8.

Honjo S, Srivatanakul P, Sriplung H, et al (2005). Genetic and environmental determinants of risk for cholangiocarcinoma via Opisthorchis viverrini in a densely infested area in Nakhon Phanom, northeast Thailand. Int J Cancer, [epub]
Kamsa-Ard S, Luvira V, Pugkhem A, et al (2015). Association between praziquantel treatment and cholangiocarcinoma: a hospital-based matched case-control study. BMC Cancer, 15, 776.

Konda LN, Pásztor Z (2001). Environmental distribution of acetochlor, atrazine, chlorpyrifos, and propisochlor under field conditions. J Agric Food Chem, 49, 3859-63.

Koompairochana V, Sonakul S, Chinda K, et al (1978). Opisthorchiasis: a clinicopathologic study of 154 cases. Southeast Asian J Trop Med Public Health, 9, 60-4.

Landis S, Murray T, Bolden S, et al (1998). Cancer statistics, 1998. CA Cancer J Clin, 48, 6-29.

Liu GX, Wu XP, Wang ZJ, et al (2010). Research progress on the relationship between three kinds of liver fluke infections and cholangiocarcinoma. Zhongguo Ji Sheng Chong Xue Yu Ji Sheng Chong Bing Za Zhi, 28, 301-5.

Marahatta SB, Punyarit P, Bhudisawasdi V, et al (2006). Polymorphism of glutathione S-transferase omega gene and risk of cancer. Cancer Lett, 236, 276-81.

Mairiang E, Elkins DB, Mairiang P, et al (1992). Relationship between intensity of Opisthorchis viverrini infection and hepatobiliary disease detected by ultrasonography. $J$ Gastroenterol Hepatol, 7, 17-21.

Mairiang E, Haswell-Elkins MR, Mairiang P, et al (1993). Reversal of biliary tract abnormalities associated with Opisthorchis viverrini infection following praziquantel treatment. Trans R Soc Trop Med Hyg, 87, 194-7.

Manwong M, Songserm N, Promthet S, et al (2013). Risk factors for cholangiocarcinoma in the lower part of Northeast Thailand: a hospital-based case-control study. Asian Pac J Cancer Prev, 14, 5953-6.

Miwa M, Honjo S, You G, et al (2014). Genetic and environmental determinants of risk for cholangiocarcinoma in Thailand. World J Gastrointest Pathophysiol, 5, 570-8.

Ozonoff D, Longnecker MP (1991). Epidemiologic approaches to assessing human cancer risk from consuming aquatic food resources from chemically contaminated water. Environ Health Perspect, 90, 141-6.

Patel T (2002). Worldwide trends in mortality from biliary tract malignancies. BMC Cancer, $2,10$.

Pilati A, Vanni MJ, González MJ, Gaulke AK (2009). Effects of agricultural subsidies of nutrients and detritus on fish and plankton of shallow-reservoir ecosystems. Ecol Appl, 19, 942-60.

Rabalais NN (2002). Nitrogen in aquatic ecosystems. Ambio, 31, 102-12.

Shin HR, Oh JK, Masuyer E, et al. (2010). Epidemiology of cholangiocarcinoma: an update focusing on risk factors. Cancer Sci, 101, 579-85.

Sithithaworn P, Pipitgool V, Srisawangwong T, et al (1997). Seasonal variation of Opisthorchis viverrini infection in cyprinoid fish in north-east Thailand: implications for parasite control and food safety. Bull World Health Organ, 75, 125-31.

Sonakul D, Koompirochana C, Chinda K, et al (1978). Hepatic carcinoma with opisthorchiasis. Southeast Asian J Trop Med Public Health, 9, 215-9.

Songserm N, Promthet S, Sithithaworn P, et al (2012). Risk factors for cholangiocarcinoma in high-risk area of Thailand: role of lifestyle, diet and methylenetetrahydrofolate reductase polymorphisms. Cancer Epidemiol, 36, 89-94.

Songserm N, Promthet S, Pientong C, et al (2014). Geneenvironment interaction involved in cholangiocarcinoma in the Thai population: polymorphisms of DNA repair genes, smoking and use of alcohol. BMJ Open, 4, 5447.

Sripa B, Brindley PJ, Mulvenna J, et al (2012). The tumorigenic liver fluke Opisthorchis viverrini-multiple pathways to 

cancer. Trends Parasitol, 28, 395-407.

Sripa B, Kaewkes S, Sithithaworn P M, et al. (2007). Liver fluke induces cholangiocarcinoma. PLoS Med, 4, 201.

Subrungruanga I, Thawornkunob C, ChawalitchewinkoonPetmitrc P, et al (2013). Gene expression profiling of intrahepatic cholangiocarcinoma. Asian Pac J Cancer Prev, 14, 557-63. Thunyaharn N, Promthet S, Wiangnon SS et al (2013). Survival of cholangiocarcinoma patients in northeastern Thailand after supportive treatment. Asian Pac J Cancer Prev, 14, 7029-32.

Viranuvatti V, Mettiyawongse S (1953). Observations on two cases of opisthorchiasis in Thailand. Ann Trop Med Parasitol, 47, 291-3.

Yeo CJ, Pitt HA, Cameron JL (1990). Cholangiocarcinoma. Surg Clin North Am, 70, 1429-47. 